\title{
A double bootstrap approach to Superposed Epoch Analysis to evaluate response uncertainty
}

\author{
Mukund P. Rao ${ }^{\mathrm{a}, \mathrm{b}, *}$, Edward R. Cook ${ }^{\mathrm{a}}$, Benjamin I. Cook ${ }^{\mathrm{c}, \mathrm{d}}$, Kevin J. Anchukaitis , $^{\mathrm{e}}$ \\ Rosanne D. D'Arrigo ${ }^{a}$, Paul J. Krusic ${ }^{\mathrm{f}, g}$, Allegra N. LeGrande ${ }^{\mathrm{c}}$ \\ a Tree Ring Laboratory, Lamont Doherty Earth Observatory of Columbia University, Palisades, NY, 10964, USA \\ ${ }^{\mathrm{b}}$ Department of Earth and Environmental Science, Columbia University, New York, NY, 10027, USA \\ ${ }^{\mathrm{c}}$ NASA Goddard Institute for Space Studies, New York, NY, 10025, USA \\ ${ }^{\mathrm{d}}$ Ocean \& Climate Physics, Lamont-Doherty Earth Observatory of Columbia University, Palisades, NY, 10964, USA \\ ${ }^{\mathrm{e}}$ Department of Geography and Development and Laboratory of Tree Ring Research, University of Arizona, Tucson, AZ, 85721, USA \\ ${ }^{\mathrm{f}}$ Department of Geography, University of Cambridge, Cambridge, CB2 3EN, UK \\ ${ }^{\mathrm{g}}$ Department of Physical Geography, Stockholm University, Stockholm, 106-91, Sweden
}

\section{A R T I C L E I N F O}

\section{Keywords:}

Tree-rings

Fire-scars

Volcanos

Wildfire

Uncertainty

Resampling

Bootstrap

Disturbance

Western US

Dendrochronology

Dendroclimatology

Paleoclimate

\begin{abstract}
A B S T R A C T
The association between climate variability and episodic events, such as the antecedent moisture conditions prior to wildfire or the cooling following volcanic eruptions, is commonly assessed using Superposed Epoch Analysis (SEA). In SEA the epochal response is typically calculated as the average climate conditions prior to and following all event years or their deviation from climatology. However, the magnitude and significance of the inferred climate association may be sensitive to the selection or omission of individual key years, potentially resulting in a biased assessment of the relationship between these events and climate. Here we describe and test a modified double-bootstrap SEA that generates multiple unique draws of the key years and evaluates the sign, magnitude, and significance of event-climate relationships within a probabilistic framework. This multiple resampling helps quantify multiple uncertainties inherent in conventional applications of SEA within dendrochronology and paleoclimatology. We demonstrate our modified SEA by evaluating the volcanic cooling signal in a Northern Hemisphere tree-ring temperature reconstruction and the link between drought and wildfire events in the western United States. Finally, we make our Matlab and R code available to be adapted for future SEA applications.
\end{abstract}

\section{Introduction}

Superposed Epoch Analysis (SEA) is a statistical method used to identify the link between discrete events and continuous time or spatiotemporal processes and test the probability of such an association occurring by chance (Haurwitz and Brier, 1981). SEA has been widely applied in climatology and dendroclimatology to test for the impact of volcanic eruptions on climate (e.g. Esper et al., 2013; Kelly et al., 1996; Kelly and Sear, 1984; Lough and Fritts, 1987; Taylor et al., 1980; Trouet et al., 2018), the significance of soil moisture and climate conditions (e.g. ENSO, PDO) on the occurrence of forest fires (e.g. Baisan and Swetnam, 1990; Gedalof et al., 2005; Hessl et al., 2004; Schoennagel et al., 2005; Swetnam, 1993; Swetnam and Betancourt, 1998; Swetnam et al., 2016), and to evaluate tree growth response to drought events (e.g. Lévesque et al., 2014; Martín-Benito et al., 2008; Orwig and
Abrams, 1997; Pederson et al., 2014; Woodhouse, 1993) and insect defoliation (Flower et al., 2014; Nola et al., 2006; Pohl et al., 2006).

SEA requires two independent datasets. The first is an 'event list'. These 'events' are usually discrete in time, such as years of volcanic eruptions or the precisely dated years of fire-scars in the annual rings of trees. The second variable is usually a long, continuous, and evenly sampled timeseries (e.g. climate observations or paleoclimate reconstructions). The underlying hypothesis of SEA is that the 'events' either cause or are themselves a response to the characteristics of the continuous timeseries, and that the identification of the sign, magnitude, and timing of that response may be optimised by averaging across all events. To evaluate this, first, a 'composite matrix' is made by drawing fixed windows of consecutive observations from the continuous timeseries that span years before, during, and after the event. The mean of this composite matrix, or its deviation from climatology is

\footnotetext{
* Corresponding author at: Tree Ring Laboratory, Lamont Doherty Earth Observatory of Columbia University, Palisades, NY, 10964, USA.

E-mail address: mukund@ldeo.columbia.edu (M.P. Rao).
} 
then calculated as the epochal response. Finally, the statistical significance of this response is determined using randomisation schemes to evaluate the result against a null hypothesis to determine how likely the observed response would have occurred by chance (Haurwitz and Brier, 1981). The compositing and averaging process serves as a filter that enhances the high-frequency response signal of interest while minimising noise (D'Arrigo et al., 1993). This technique also accounts for long-term drift, or low frequency variability that may be present. For example, using SEA one can infer that volcanic eruptions cause widespread northern hemisphere cooling (e.g. Anchukaitis et al., 2017; Briffa et al., 1998; Sear et al., 1987; Stoffel et al., 2015), or that fireevents are associated with anomalously dry soil moisture conditions (e.g. Hessl et al., 2016; Kipfmueller et al., 2017).

Within the SEA literature the two commonly used randomisation schemes to determine response significance are 'random bootstrapping' (Haurwitz and Brier, 1981) and 'block reshuffling' (Adams et al., 2003). While both rely on Monte Carlo type bootstrapping approaches to determine confidence interval thresholds, they test for different hypotheses (Anchukaitis et al., 2010). The random bootstrap takes multiple random draws from the entire 'event' timeseries by generating 'pseudo key years', and then computes statistics of random variability within the 'response' dataset to determine significance thresholds. The block reshuffling method on the other hand creates random surrogate composite matrices by first permuting the original 'event' composite matrix, and then computing distributions based on this random shuffling of the 'response' anomalies for each event series (Wanliss et al., 2018). Prior to the reshuffling, the serial autocorrelation of the 'response' timeseries is used to determine the block length sampled, helping preserve the data's autocorrelation structure. By resampling in blocks, exclusively within the composite matrix, the statistics and autocorrelation of the composite matrix are preserved while destroying preferred pre and post-event temporal ordering, ensuring that the resulting confidence intervals take into account the confounding influence of temporal structure in the time series (Adams et al., 2003).

While the compositing and averaging process in SEA serves as a high-frequency filter to increase the signal-to-noise ratio of the mean epochal response, it has multiple drawbacks. The first is that one or more events might have an outsized leverage on the mean response value across epochs (Adams et al., 2003). The second relates to noise added to the SEA results due to dating uncertainty in the events (Sig1 et al., 2015; Toohey and Sigl, 2017) or the timeseries, along with the potential lack of temporal resolution in the proxy to resolve the seasonality of the event or the response. The dating uncertainty means that there might be an offset between the event response (e.g. as post-volcanic winter warming (Zambri et al., 2017)) and what is recorded in the seasonal climate proxies like as tree-rings and corals. Another source of uncertainty in SEA is the a priori subjective definition of what constitutes an event and the effect this choice has on the SEA response. For example, the threshold to use to define a volcanic event (e.g. radiative forcing larger than Pinatubo, Tambora, etc.), or the percentage cut-off used to define fire events (e.g. 10\% scarred trees, $20 \%$ scarred trees etc.) tend to be subjective choices. Finally, the simple averaging of the response matrix in conventional SEA relies on the implicit hypothesis that all event signals are equal when in reality each event (e.g. volcanic eruption, fire year) is unique. Additionally, even the response to the same kind of event might differ due to natural variability within the climate system modulated by pre-event background states (Esper et al., 2013; Fischer et al., 2007; Zanchettin et al., 2019).

Here in this study we describe a modified double-bootstrap SEA framework that first generates multiple unique draws of the key year list itself. We first used this method in Rao et al. (2017) to evaluate the impact of volcanic eruptions on post-volcanic hydroclimate over Europe and North Africa. This double-bootstrap SEA methodology describes the event response in a probabilistic framework and therefore explicitly and quantitatively addresses the uncertainties in SEA mentioned above.
Table 1

Tropical volcanic eruptions key years used for Superposed Epoch Analysis (SEA) and Northern Hemisphere marker years highlighted in Fig. 1. Dates are derived from Toohey and Sigl (2017). Names are mentioned only for identified eruptions.

\begin{tabular}{ll}
\hline Tropical volcanic eruptions & $\begin{array}{l}\text { Northern Hemisphere Extratropical } \\
\text { eruptions }\end{array}$ \\
\hline 1107 & 1182 \\
1170 & 1200 \\
1229 & 1210 \\
1257 Rinjani, Samalas, Indonesia & 1329 \\
1285 & 1477 Bárðarbunga, Veiðivötn, \\
& Veidivatnahraun, Iceland \\
1344 & 1667 Shikotsu, Tarumai, Japan \\
1452 & 1729 \\
1457 & 1783 Grimsvötn, Lakagígar, Laki, Iceland \\
1585 Colima, México & 1912 Novarupta, Katmai, Alaska, USA \\
1600 Huaynaputina, Peru & \\
1694 & \\
1640 Parker, Philippines & \\
1808 & \\
1815 Tambora, Indonesia & \\
1831 Babuyan Claro, Philippines & \\
1835 Cosigüina, Nicaragua & \\
1883 Krakatau, Indonesia & \\
1902 Santa Maria, Guatemala & \\
1991 Pinatubo, Philippines & \\
\hline
\end{tabular}

\section{Data}

We test our modified SEA method using two datasets. The first is a recent tree ring reconstruction of Northern Hemisphere May-thoughAugust mean temperature spanning 750-2011 C.E. (N-TREND -Wilson et al., 2016). The second is a compilation of annually resolved tree ring based fire scar records from the western United States (Trouet et al., 2010). The original authors of both papers and datasets also conducted SEA analysis, demonstrating that Northern Hemisphere temperatures cool in the years immediately following large tropical volcanic eruptions (Wilson et al., 2016), and wildfire years in the western US coincide with drought years (Trouet et al., 2010). Hence, we focus on the implementation of our SEA method and do not seek to reinterpret the physical mechanisms behind the event signals.

The tropical eruptions key years used to evaluate the N-TREND temperature reconstruction response to volcanism come from the eVolv2k database (Toohey and Sigl, 2017). We chose a total of 20 tropical eruptions, between $30^{\circ} \mathrm{S}-30^{\circ} \mathrm{N}$ and 1100-2011 C.E. that have a peak northern hemisphere aerosol optical depth (AOD) greater than 0.08 as eruption key years (Table 1 ). Fig. 1 shows the N-TREND temperature reconstruction between 1100-2011 C.E. along with markers for these volcanic eruptions. For reference, we also include markers for 9 northern hemisphere extratropical volcanic eruptions between $30^{\circ} \mathrm{N}$ $90^{\circ} \mathrm{N}$ (Table 1) with northern hemisphere AOD $>0.08$ from Toohey and Sigl (2017). Following Trouet et al. (2010), we categorised a year as a fire-year when at least 10 percent of samples are scarred in a minimum of two trees, resulting in a total of 98 candidate fire key years between 1342-1952 C.E.

The record for the western US used to evaluate drought conditions during fire-event epochs comes from an area-weighted spatial average of the Living Blended Drought Atlas (LBDA) (Cook et al., 2010, 2004) between $124^{\circ} \mathrm{W}$ to $109{ }^{\circ} \mathrm{W}$ and $35^{\circ} \mathrm{N}$ to $50{ }^{\circ} \mathrm{N}$, covering all four regional composite fire scar series used in Trouet et al. (2010). The LBDA is a gridded spatial reconstruction of mean June through August (JJA) Palmer Drought Severity Index (PDSI - Palmer, 1965). Fig. 2a shows the percentage of all the western US trees within the Trouet et al. (2010) dataset that records a fire for each year between 1300-2000 C.E. along with the total number of trees. The lower panel Fig. $2 \mathrm{~b}$ is a timeseries of the area-weighted PDSI for the western US, with negative and positive 


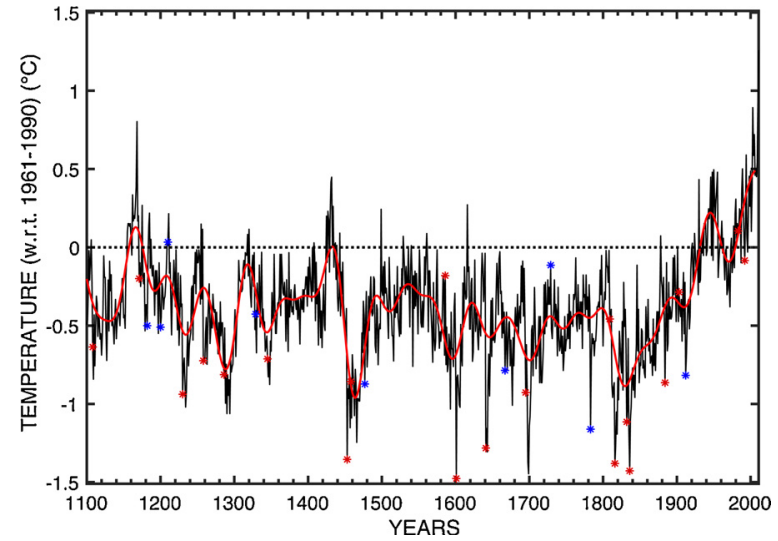

Fig. 1. A temporal subset of the Northern Hemisphere May-August summer temperature reconstruction between 1100-2011 C.E. from Wilson et al. (2016). Red * symbols indicate tropical volcanic eruption key years (see Data) used in our Superposed Epoch Analysis (SEA) to evaluate the Northern Hemisphere summer temperature response to volcanism. Blue * symbols indicate large extratropical Northern Hemisphere eruptions. Tropical volcanic key years are shifted by +1 years to better align with the cooling response (see Results). Yaxis is the anomaly in ${ }^{\circ} \mathrm{C}$ with respect to temperatures between 1961-1990.

values indicating dry and wet conditions respectively.

\section{Methods}

The first step of SEA analysis is to develop a composite matrix of event responses. In traditional SEA, rows of the composite matrix each correspond to a key or event year, while columns contain are the data from the time series prior to, during, and following each event (Haurwitz and Brier, 1981). The number of columns depends on the window length of interest. In both examples we chose a window length of 21 years, spanning from 5 years pre-event to 15 years post-event. Year 0 , the sixth column in the matrix, therefore corresponds to either a volcanic event year or a fire year. However, unlike conventional SEA, where only one composite matrix is developed for all key year responses, we developed 1000 unique versions of composite matrices by drawing unique subsets of key years at random without replacement from the key year list.

We draw unique subsets without replacement for two reasons. The first is to avoid biasing each iteration of the composite matrix by drawing the same year multiple times within one draw, and the second is to avoid biasing the final epochal mean probability distribution by making multiple draws with the same combination of key years. The total number of volcanic key years is 20 , and the total number of fire key years is 98 . For the volcanic forcing SEA experiment, we made 1000 composite matrices using unique random combinations of 10 volcanic key years without replacement, while for the fire-event drought SEA we made 1000 unique composite matrices drawing of 50 random fire key years without replacement. While the choice of 10 volcanic and 50 fire year years is relatively arbitrary, these numbers represent approximately half the total number of key events in the dataset, thus giving us reasonable estimates of spread in the response.

We normalised the rows of each composite matrix by subtracting the five-year pre-event mean. This subtraction reduces the impact lowfrequency climate variability has on the final epochal mean, and the likelihood that one large event leverages and biases the overall epochal mean of the composite matrix (Adams et al., 2003). Other approaches to normalization include, i. calculating the epochal response as zscores reflecting scaled deviations as done within the $\mathrm{R}$ ( $\mathrm{R}$ Core Team, 2017) package 'dplR' (Bunn, 2008), and ii. calculating the departures of the climate series from average climate conditions as done in the $\mathrm{R}$ package 'burnr' (Malevich et al., 2018). Finally, for each for the 1000 unique composite matrices we calculated the epochal mean by averaging
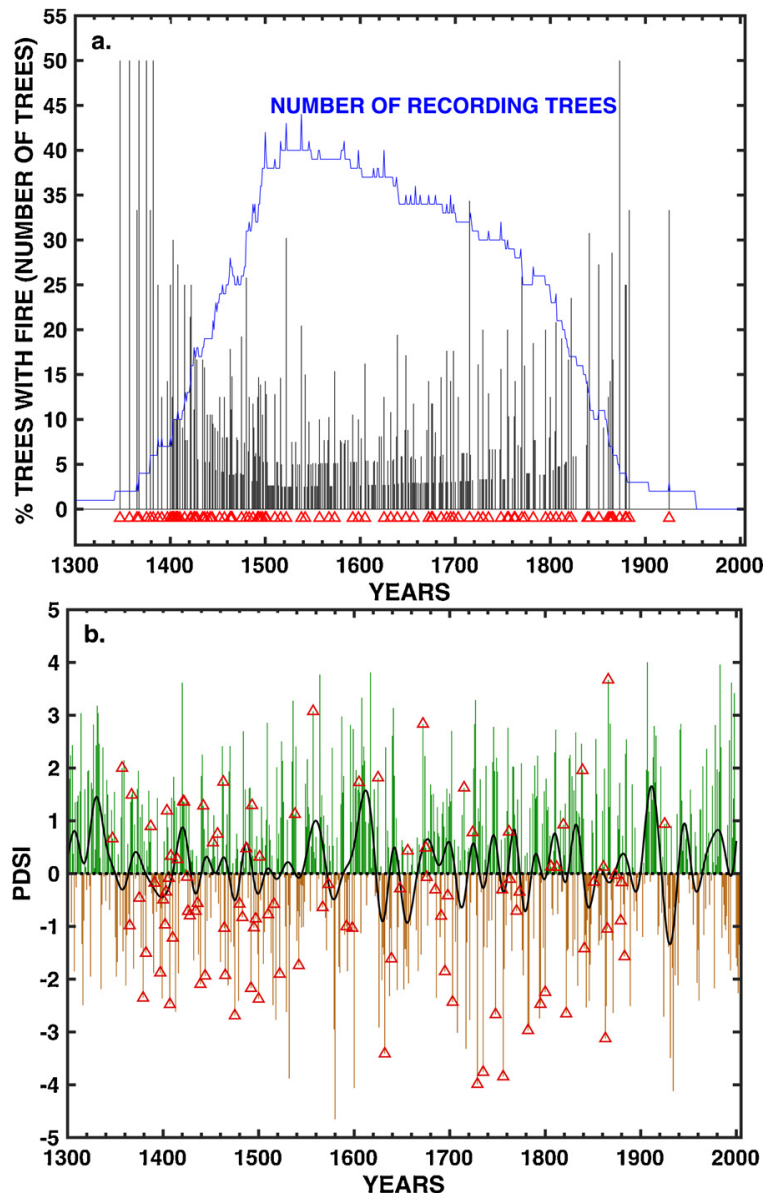

Fig. 2. Fire event and drought history for the western US between 1300-2005 C.E. (a) Percentage of trees from the Trouet et al. (2010) western US compilation that record a fire in a given year (vertical black bars) along with the total number of recording trees (in blue). Red triangles are the final set of 98 candidate fire event key years chosen using a cut-off of at least $10 \%$ of scarred samples with a minimum of 2 recording trees. (b) Area-weighted spatial average of mean June-August Palmer Drought Severity Index (JJA PDSI) for the western US $\left(124^{\circ} \mathrm{W}-109^{\circ} \mathrm{W}\right.$ d $\left.35^{\circ} \mathrm{N}-50{ }^{\circ} \mathrm{N}\right)$ from the Living Blended Drought Atlas (Cook et al., 2010). The 98 red triangle symbols are the same fire event key years from part (a).

across each lag, and calculated the final response as the $5^{\text {th }}$ percentile, median, and $95^{\text {th }}$ percentile of the 1000 epochal mean responses.

We determined the statistical response of the $5^{\text {th }}$ percentile, median, and $95^{\text {th }}$ percentile epochal mean responses using both random bootstrapping and block reshuffling (Adams et al., 2003; Davi et al., 2015). In both methods, we generated 10,000 iterations of pseudo-composite matrices. For the random bootstrap this was done by drawing sets of pseudo key-years sampled over the entire timeseries. To be consistent with how the final epochal response was calculated, the pseudo- composite matrices were generated by drawing 10 and 50 pseudo key years at random from the Wilson et al. (2016) temperature and Cook et al. (2010) PDSI reconstructions respectively. Each set of block reshuffling surrogate matrices was generated by first drawing one of the 1000 composite matrices at random and then randomly reshuffling blocks of the chosen matrix. The length of each block was determined as twice the e-folding distance of the first-order auto-correlation (AR1) of the temperature and PDSI reconstructions, calculated as $-2 / \ln (\rho)$; where $\rho$ is the value of the AR1 coefficient (Adams et al., 2003).

These pseudo composite matrices were normalised in the same fashion as the actual composite matrices by subtracting the five-year pre-event mean. Finally, the $1^{\text {st }}, 5^{\text {th }}, 10^{\text {th }}, 90^{\text {th }}, 95^{\text {th }}$, and $99^{\text {th }}$ percentiles of the epochal means of the pseudo composite matrix were 


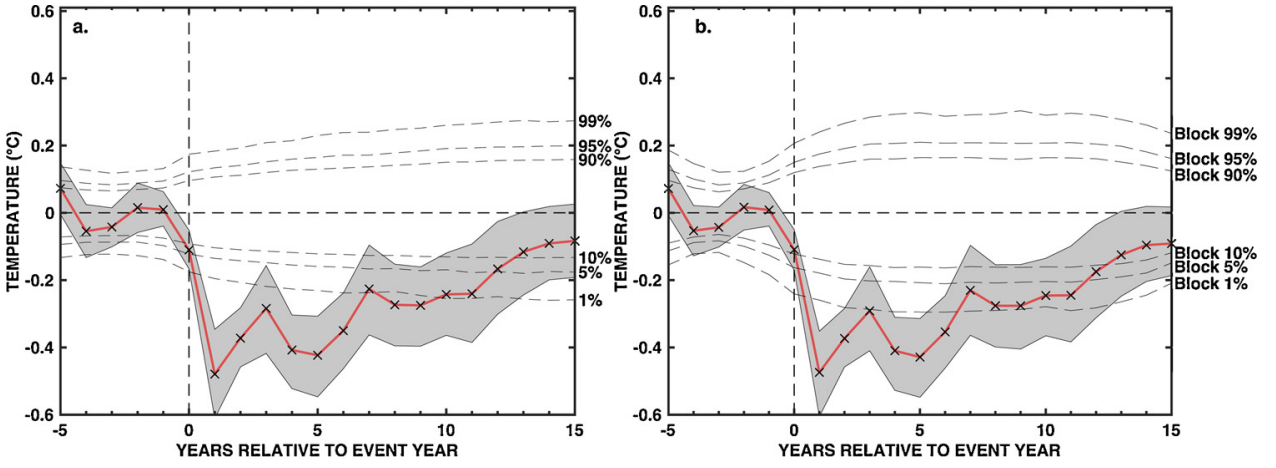

Fig. 3. Superposed Epoch Analysis (SEA) showing May-August northern hemisphere temperature cooling response to tropical volcanism between 1100-2011 C.E. Uncertainty intervals are 5th and 95th percentiles of the temperature response, while the horizontal lines indicate the threshold required for epochal anomalies to be statistically significant using random bootstrapping (a) and block bootstrapping (b). calculated as the significance thresholds needed to be exceeded for the SEA response to be deemed statistically significant.

\section{Results and discussion}

Our SEA on the northern hemisphere May-August temperature reconstruction shows strong and significant $(\mathrm{p}<0.01)$ cooling in the years following a volcanic eruption and lasting up to 6 years posteruption (Fig. 3 and Wilson et al., 2016). This result is consistent regardless of whether we use the random bootstrap or block reshuffling methods to test for significance. The strongest cooling response of $-0.47^{\circ} \mathrm{C}$, relative to the five-year pre-event mean, occurs one-year post-eruption (i.e. year $t+1$ ). The bootstrapped $5^{\text {th }}$ and $95^{\text {th }}$ percentile confidence intervals of the response also show significant cooling $(\mathrm{p}<0.01)$. The $5^{\text {th }}$ and $95^{\text {th }}$ percentile response represents the degree of variability in the volcanic response based on choices of 1000 unique sets of 10 key years from a total of 20 potential key years. That the $95^{\text {th }}$ percentile response in year $t+1$ also shows significant cooling ( $p<0.01$ ) indicates that even the warmest responses in the post-volcanic period are cooler than what would be expected by random variability.

SEA on the Trouet et al. (2010) western US fire event dataset shows that fire-events are coincident with anomalously dry years (Fig. 4 and Trouet et al., 2010). Median JJA PDSI in fire years is -0.7 units lower than the five-year pre-event mean PDSI. The $95^{\text {th }}$ percentile of PDSI conditions in fire years, which represents a choice of 'wetter' fire-event responses, calculated by drawing 1000 sets of 50 unique fire key years at random without replacement from the total list of 98 possible fire years is significant at $p<0.05$ while the median and $5^{\text {th }}$ percentile response are significant at $\mathrm{p}<0.001$. In both examples the block bootstrapping and block reshuffling methods produces similarly wide confidence intervals (Figs. $3 \& 4$ ). This suggests that, at least in these two cases scrambling the composite matrix to destroy temporal ordering generates similar variability as sampling from the entire timeseries.

Our choice of drawing the 1000 unique composite matrices from 10 unique volcanic key years at random out of a possible 20 years, and 50 fire key years at random from a total of 98 was based on a choice to keep the number of event years in each unique draw small enough to be able to sample the variability in the response, but at the same time large enough that the epochal mean of each composite matrix can still serve as a high-frequency filter to separate common signal from noise. However, we do note that this choice of the number of key years in each draw (10 eruptions out of 20; 50 fire years out of 98), does impart an additional source of uncertainty the SEA procedure, as the width of the shaded uncertainty intervals in Fig. 3 and errorbars in Fig. 4 are functions of the sample size chosen in the bootstrap. While we use the median response to evaluate statistical significance, the presented shaded uncertainty intervals and errorbars provide a better estimate of variability in the response as is inherent in the data than is provided in conventional SEA. For example, by calculating the variability in the post-volcanic climate response (Fig. 3), and evaluating the variability in drought conditions coincident with fire years (Fig. 4), we more effectively account for the fact that not all volcanic events produce the same climate response, and that the magnitude of drought conditions coincident with fire events can be quite variable. Conventional SEA omits this variability by presenting the final response as the simple average of the normalised composite matrix or as symmetric error bars around the mean, which might not be representative of the actual variability, or skewness in the event response distribution.

This variability in response is also evident when evaluating the temperature reconstruction in Fig. 1 and the JJA PDSI reconstruction in Fig. 2. For example, warm temperatures are reconstructed by Wilson et al. (2016) in 1586 following the eruption of Colima in 1585. The reasons for the variability in the volcanic response likely include the location of the volcano, stratospheric ejection height, the physical characteristics and spatial distribution of sulphate aerosols, the background climate state, the seasonality of the eruption, and the possibility that the timing of peak forcing might not coincide with the climatesensitivity of the climate-proxy used (Guillet et al., 2017; Pausata et al., 2016; Zanchettin et al., 2019). The variability in drought conditions during fire event years is even more evident. The error bars around PDSI conditions coincident with fire-events in year $t+0$ is negatively skewed. This can be explained by the number of fire events that take
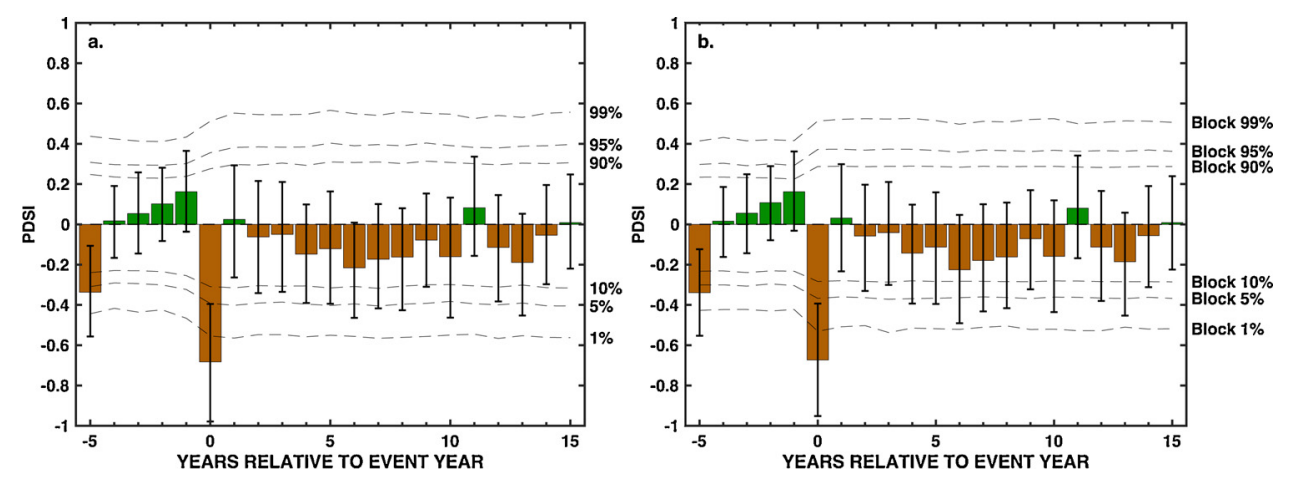

Fig. 4. SEA showing that western US fireevents are coincident with dry June-August PDSI conditions as reconstructed by the Cook et al. (2010) Living Blended Drought Atlas in year $t+0$. Similar to Fig. 3, uncertainty intervals are 5th and 95th percentiles of the drought conditions during fire events, while the horizontal lines indicate the threshold required for epochal anomalies to be statistically significant using random bootstrapping (a) and block bootstrapping (b). 
place during dry versus wet years (Fig. 2). Of the 98 fire events, 65 occur when PDSI is less than 0 while 33 events occurred when PDSI is greater than 0. Evaluating fire events during more extreme PDSI values, 17 fire events occur when PDSI is less than -2, while only 3 fire events occur when PDSI is greater than 2. Reasons for variability in drought conditions during fire-event years include the influence of fuel availability and ignition sources on wildfire occurrence (Abatzoglou and Williams, 2016; Bessie and Johnson, 1995; Gedalof et al., 2005; Littell et al., 2009, 2016; Trouet et al., 2010; Westerling et al., 2003) uncertainties in the underlying drought reconstruction (Cook et al., 2010), and any uncertainties in defining wildfire event years based on the existing fire scar network (Falk et al., 2011). All of these observations highlight the contingent and variable nature of event-climate associations.

Our double-bootstrap SEA makes multiple draws of subsets from the key year list and thus presents SEA results in a way that attempts to explicitly account for the influence of these processes during key years. Additionally, by treating key years as random variables we more formally acknowledge that the key year dates for volcanic eruptions might be uncertain (Toohey and Sigl, 2017), and that the definition of event years as used here (eruptions with a peak northern hemisphere AOD $>0.08$; at least $10 \%$ scarred trees with a minimum of 2 samples) is somewhat arbitrary. While in this study we conducted SEA on two selected timeseries, it is possible to expand this to evaluate SEA responses within a spatial context as well. For example, in Rao et al. (2017) we applied this double-bootstrap approach to evaluate the post-volcanic drought response and associated variability over Europe and northern Africa. An additional benefit is that our SEA approach allows us to place additional constraints on the calculation of the epochal mean to avoid the selection of closely spaced volcanic eruptions such as, 1452/1457 and $1808 / 1815$, and fire-years in each unique draw. This reduces bias in the final estimated epochal response by minimising the number of overlapping windows. In the end, even though SEA is only a statistical test of association between the event list and the variable of interest (Haurwitz and Brier, 1981), our implementation of a bootstrapped resampling of the key year list provides a statistical framework to explicitly quantify the variability in this association while explicitly acknowledging the uniqueness of each event.

\section{Acknowledgements}

The authors thank the Past Global Changes - Volcanic Impacts on Climate and Society (PAGES-VICS) working group members for helpful feedback at the $3^{\text {rd }}$ VICS meeting held at Tucson, AZ, USA in January 2018 and Matt Toohey for providing the volcanic eruption key year list. Lamont Contribution \# 8313. KJA is supported by NOAA grant NA18OAR4310420 and NSF grant AGS-1501834.

The full N-TREND Wilson et al. (2016) data can be downloaded at https://ntrenddendro.wordpress.com/. The Trouet et al. (2010) fire data are available at the International Multiproxy Paleofire Database at http://www.ncdc.noaa.gov/paleo/impd/paleofire.html. The Cook et al., 2010 Living Blended Drought Atlas is available at https://www. ncdc.noaa.gov/paleo-search/.

The datasets and $\mathrm{R}$ and Matlab code used to this study are available at https://doi.org/10.17632/8p7y29hz5h.1.

\section{References}

Abatzoglou, J.T., Williams, A.P., 2016. Impact of anthropogenic climate change on wildfire across western US forests. Proc. Natl. Acad. Sci. 113 (42), 11770-11775. https://doi.org/10.1073/pnas.1607171113.

Adams, J.B., Mann, M.E., Ammann, C.M., 2003. Proxy evidence for an El Niño-like response to volcanic forcing. Nature 426, 274. https://doi.org/10.1038/nature02101.

Anchukaitis, K.J., Buckley, B.M., Cook, E.R., et al., 2010. Influence of volcanic eruptions on the climate of the Asian monsoon region. Geophys. Res. Lett. 37 (22). https://doi. org/10.1029/2010GL044843.

Anchukaitis, K.J., Wilson, R., Briffa, K.R., et al., 2017. Last millennium Northern Hemisphere summer temperatures from tree rings: part II, spatially resolved reconstructions. Quat. Sci. Rev. 163, 1-22.

Baisan, C.H., Swetnam, T.W., 1990. Fire history on a desert mountain range: rincon Mountain Wilderness, Arizona, U.S.A. Can. J. For. Res. 20 (10), 1559-1569. https:// doi.org/10.1139/x90-208.

Bessie, W.C., Johnson, E.A., 1995. The relative importance of fuels and weather on fire behavior in subalpine forests. Ecology 76 (3), 747-762. https://doi.org/10.2307/ 1939341.

Briffa, K.R., Jones, P.D., Schweingruber, F.H., et al., 1998. Influence of volcanic eruptions on Northern Hemisphere summer temperature over the past 600 years. Nature 393, 450. https://doi.org/10.1038/30943.

Bunn, A.G., 2008. A dendrochronology program library in R (dplR). Dendrochronologia 26 (2), 115-124.

Cook, E.R., Woodhouse, C.A., Eakin, C.M., et al., 2004. Long-term aridity changes in the Western United States. Science 306 (5698), 1015-1018. https://doi.org/10.1126/ science. 1102586 .

Cook, E.R., Seager, R., Heim Jr, R.R., et al., 2010. Megadroughts in North America: placing IPCC projections of hydroclimatic change in a long-term palaeoclimate context. J. Quat. Sci. 25 (1), 48-61. https://doi.org/10.1002/jqs.1303.

D'Arrigo, R.D., Cook, E.R., Jacoby, G.C., et al., 1993. Nao and sea surface temperature signatures in tree-ring records from the North Atlantic sector. Quat. Sci. Rev. 12 (6), 431-440.

Davi, N.K., D’Arrigo, R., Jacoby, G.C., et al., 2015. A long-term context (931-2005 C.E.) for rapid warming over Central Asia. Quat. Sci. Rev. 121, 89-97.

Esper, J., Schneider, L., Krusic, P.J., et al., 2013. European summer temperature response to annually dated volcanic eruptions over the past nine centuries. Bull. Volcanol. 75 (7), 736. https://doi.org/10.1007/s00445-013-0736-z.

Falk, D.A., Heyerdahl, E.K., Brown, P.M., et al., 2011. Multi-scale controls of historical forest-fire regimes: new insights from fire-scar networks. Front. Ecol. Environ. 9 (8), 446-454. https://doi.org/10.1890/100052.

Fischer, E.M., Luterbacher, J., Zorita, E., et al., 2007. European climate response to tropical volcanic eruptions over the last half millennium. Geophys. Res. Lett. 34 (5). https://doi.org/10.1029/2006GL027992.

Flower, A., Gavin, D.G., Heyerdahl, E.K., et al., 2014. Drought-triggered western spruce budworm outbreaks in the interior Pacific Northwest: a multi-century dendrochronological record. For. Ecol. Manage. 324, 16-27.

Gedalof, Ze., Peterson, D.L., Mantua, N.J., 2005. Atmospheric, climatic, and ecological controls on extreme wildfire years in the northwestern United States. Ecol. Appl. 15 (1), 154-174. https://doi.org/10.1890/03-5116.

Guillet, S., Corona, C., Stoffel, M., et al., 2017. Climate response to the Samalas volcanic eruption in 1257 revealed by proxy records. Nat. Geosci. 10, 123. https://doi.org/10. 1038/ngeo2875.

Haurwitz, M.W., Brier, G.W., 1981. A critique of the superposed epoch analysis method: its application to solar-weather relations. Mon. Weather. Rev. 109 (10), 2074-2079 doi:10.1175/1520-0493(1981)109 < 2074:Acotse > 2.0.Co;2.

Hessl, A.E., McKenzie, D., Schellhaas, R., 2004. Drought and Pacific Decadal Oscillation linked to fire occurrence in the inland Pacific Northwest. Ecol. Appl. 14 (2), 425-442. https://doi.org/10.1890/03-5019.

Hessl, A.E., Brown, P., Byambasuren, O., et al., 2016. Fire and climate in Mongolia (1532-2010 common era). Geophys. Res. Lett. 43 (12), 6519-6527. https://doi.org/ 10.1002/2016GL069059.

Kelly, P.M., Sear, C.B., 1984. Climatic impact of explosive volcanic eruptions. Nature 311 (5988), 740-743. https://doi.org/10.1038/311740a0.

Kelly, P.M., Jones, P.D., Pengqun, J., 1996. The spatial response of the climate system to explosive volcanic eruptions. Int. J. Climatol. 16 (5), 537-550.

Kipfmueller, K.F., Schneider, E.A., Weyenberg, S.A., et al., 2017. Historical drivers of a frequent fire regime in the red pine forests of Voyageurs National Park, MN, USA. Forest Ecol. Manag. 405, 31-43.

Lévesque, M., Rigling, A., Bugmann, H., et al., 2014. Growth response of five co-occurring conifers to drought across a wide climatic gradient in Central Europe. Agric. For. Meteorol. 197, 1-12.

Littell, J.S., McKenzie, D., Peterson, D.L., et al., 2009. Climate and wildfire area burned in western U.S. ecoprovinces, 1916-2003. Ecol. Appl. 19 (4), 1003-1021. https://doi. org/10.1890/07-1183.1.

Littell, J.S., Peterson, D.L., Riley, K.L., et al., 2016. A review of the relationships between drought and forest fire in the United States. Glob. Chang. Biol. 22 (7), 2353-2369. https://doi.org/10.1111/gcb.13275.

Lough, J.M., Fritts, H.C., 1987. An assessment of the possible effects of volcanic eruptions on North American climate using tree-ring data, 1602 to 1900 A.D. Clim. Change 10 (3), 219-239. https://doi.org/10.1007/bf00143903.

Malevich, S.B., Guiterman, C.H., Margolis, E.Q., 2018. Burnr: fire history analysis and graphics in R. Dendrochronologia 49, 9-15.

Martín-Benito, D., Cherubini, P., del Río, M., et al., 2008. Growth response to climate and drought in Pinus nigra Arn. Trees of different crown classes. Trees 22 (3), 363-373.

Nola, P., Morales, M., Motta, R., et al., 2006. The role of larch budmoth (Zeiraphera diniana Gn.) on forest succession in a larch (Larix decidua Mill.) and Swiss stone pine (Pinus cembra L.) stand in the Susa Valley (Piedmont, Italy). Trees 20 (3), 371-382. https://doi.org/10.1007/s00468-006-0050-x.

Orwig, D.A., Abrams, M.D., 1997. Variation in radial growth responses to drought among species, site, and canopy strata. Trees 11 (8), 474-484. https://doi.org/10.1007/ s004680050110.

Palmer, W.C., 1965. Meteorological Drought, vol. 30 US Department of Commerce, Weather Bureau Washington, DC, USA.

Pausata, F.S.R., Karamperidou, C., Caballero, R., et al., 2016. ENSO response to highlatitude volcanic eruptions in the Northern Hemisphere: the role of the initial conditions. Geophys. Res. Lett. 43 (16), 8694-8702. https://doi.org/10.1002/ 2016 gl069575. 
Pederson, N., Dyer, J.M., McEwan, R.W., et al., 2014. The legacy of episodic climatic events in shaping temperate, broadleaf forests. Ecol. Monogr. 84 (4), 599-620. https://doi.org/10.1890/13-1025.1.

Pohl, K.A., Hadley, K.S., Arabas, K.B., 2006. Decoupling Tree-Ring Signatures of Climate Variation, Fire, and Insect Outbreaks in Central Oregon, vol. 62 SPIE.

R Core Team, 2017. R: a Language and Environment for Statistical Computing. URL. R Foundation for Statistical Computing, Vienna, Austria. https://www.R-project.org/.

Rao, M.P., Cook, B.I., Cook, E.R., et al., 2017. European and Mediterranean hydroclimate responses to tropical volcanic forcing over the last millennium. Geophys. Res. Lett. 44 (10), 5104-5112. https://doi.org/10.1002/2017GL073057.

Schoennagel, T., Veblen, T.T., Romme, W.H., et al., 2005. ENSO and PDO variability affect DROUGHT-INDUCED fire occurrence in Rocky Mountain subalpine forests. Ecol. Appl. 15 (6), 2000-2014. https://doi.org/10.1890/04-1579.

Sear, C.B., Kelly, P.M., Jones, P.D., et al., 1987. Global surface-temperature responses to major volcanic eruptions. Nature 330, 365. https://doi.org/10.1038/330365a0.

Sigl, M., Winstrup, M., McConnell, J.R., et al., 2015. Timing and climate forcing of volcanic eruptions for the past 2,500 years. Nature 523 (7562), 543-549. https://doi. org/10.1038/nature14565.

Stoffel, M., Khodri, M., Corona, C., et al., 2015. Estimates of volcanic-induced cooling in the Northern Hemisphere over the past 1,500 years. Nat. Geosci. 8, 784. https://doi. org/10.1038/ngeo2526.

Swetnam, T.W., 1993. Fire history and climate change in giant Sequoia groves. Science 262 (5135), 885-889. https://doi.org/10.1126/science.262.5135.885.

Swetnam, T.W., Betancourt, J.L., 1998. Mesoscale disturbance and ecological response to decadal climatic variability in the american southwest. J. Clim. 11 (12), 3128-3147 doi:10.1175/1520-0442(1998)011 < 3128:Mdaert > 2.0.Co;2.

Swetnam, T.W., Farella, J., Roos, C.I., et al., 2016. Multiscale perspectives of fire, climate and humans in western North America and the Jemez Mountains, USA. Philosophical transactions of the royal society B. Biol. Sci. 371 (1696), 20150168. https://doi.org/ $10.1098 /$ rstb. 2015.0168.

Taylor, B.L., Gal-Chen, T., Schneider, S.H., 1980. Volcanic eruptions and long-term temperature records: an empirical search for cause and effect. Q. J. R. Meteorol. Soc. 106 (447), 175-199. https://doi.org/10.1002/qj.49710644712.

Toohey, M., Sigl, M., 2017. Volcanic stratospheric sulfur injections and aerosol optical depth from 500 BCE to 1900 CE. Earth Syst. Sci. Data Discuss. 9 (2), 809-831. https://doi.org/10.5194/essd-9-809-2017.

Trouet, V., Taylor, A.H., Wahl, E.R., et al., 2010. Fire-climate interactions in the American West since 1400 CE. Geophys. Res. Lett. 37 (4). https://doi.org/10.1029/ 2009GL041695.

Trouet, V., Babst, F., Meko, M., 2018. Recent enhanced high-summer North Atlantic Jet variability emerges from three-century context. Nat. Commun. 9 (1), 180. https:// doi.org/10.1038/s41467-017-02699-3.

Wanliss, J., Cornélissen, G., Halberg, F., et al., 2018. Superposed epoch analysis of physiological fluctuations: possible space weather connections. Int. J. Biometeorol. 62 (3), 449-457. https://doi.org/10.1007/s00484-017-1453-7.

Westerling, A.L., Gershunov, A., Brown, T.J., et al., 2003. Climate and wildfire in the Western United States. Bull. Am. Meteorol. Soc. 84 (5), 595-604. https://doi.org/10. 1175/bams-84-5-595.

Wilson, R., Anchukaitis, K., Briffa, K.R., et al., 2016. Last millennium northern hemisphere summer temperatures from tree rings: part I: the long term context. Quat. Sci. Rev. 134, 1-18.

Woodhouse, C., 1993. Tree-growth response to ENSO events in the central colorado front range. Phys. Geogr. 14 (5), 417-435. https://doi.org/10.1080/02723646.1993. 10642489.

Zambri, B., LeGrande, A.N., Robock, A., et al., 2017. Northern Hemisphere winter warming and summer monsoon reduction after volcanic eruptions over the last millennium. J. Geophys. Res. Atmos. 122 (15), 7971-7989. https://doi.org/10.1002/ 2017JD026728.

Zanchettin, D., Timmreck, C., Toohey, M., et al., 2019. Clarifying the relative role of forcing uncertainties and initial-condition unknowns in spreading the climate response to volcanic eruptions. Geophys. Res. Lett. 46 (3), 1602-1611. https://doi.org/ $10.1029 / 2018 g 1081018$. 